\title{
A comparative review of Asian and British-born maternity patients in Bradford, 1974-8
}

\author{
K. M. LUMB \\ From the Community Health Service, Bradford Area Health Authority \\ P. J. CONGDON AND G. T. LEALMAN \\ From the Bradford Children's Hospital, Bradford
}

SUMMARY The perinatal mortality rate for Asian babies born in Bradford during the five years 1974-8 was persistently higher than for babies born to United Kingdom mothers. A comparative review of 18924 British indigenous and 6443 Asian immigrant maternity patients delivered in Bradford from 1974-8 demonstrated several differences between the two ethnic groups. Factors operating in favour of Asian women were fewer teenage mothers, lower rates of illegitimacy, and fewer smokers. On the other hand, a greater number of factors presented increased risks to Asian patients-more women aged over 35, lower social class, higher parity, shorter pregnancy intervals, previous perinatal deaths, shorter duration of antenatal care, anaemia, shorter gestations, more babies born without professional help, and more low-birthweight babies. Local health education programmes are now concentrating on encouraging expectant mothers to attend early and regularly for antenatal care, to breast-feed their babies, and to increase the interval between pregnancies to at least one year.

Bradford has a large and increasing Asian population. In 1978, $28 \%$ of the babies born in the Bradford Health District were to Asian mothers, while in the same year in England and Wales $8 \%$ of the births were to mothers from the New Commonwealth and Pakistan. ${ }^{1}$ At the time of the British Births study in 1970,2\% of the births were to mothers born in India and Pakistan and the perinatal rate for singleton births was 21 per 1000 births for English babies and 32 for Indian/Pakistani babies. ${ }^{2}$

Britain's present record in the field of perinatal mortality and maternity care has been the subject of recent critical comment, ${ }^{34}$ but detailed discussion has not been focused on the possible influence of ethnic differences on the outcome of pregnancies in this country.

A study in Bradford in 1969 drew attention to certain health risks for Asian immigrant mothers and their children, but reported that the perinatal mortality rate (PNMR) for Asian babies had declined steeply from 1965 to 1969 , so that in 1969 the rates for Asian and non-Asian babies were almost the same (27 and 26 per 1000 respectively). ${ }^{3}$ During the five years 1974-8 the PNMR for Asian births in Bradford has been persistently higher than for all other births in the city (Figure).
It is the purpose of this paper to compare pregnant women delivered in Bradford from 1974-8 who were born in Asia with women born in Britain and

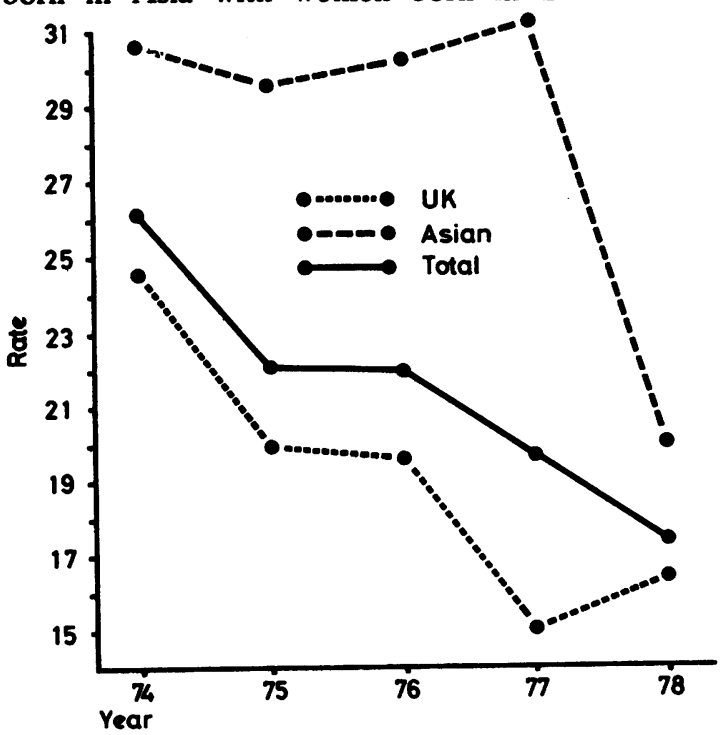

Figure Perinatal mortality rates, Bradford Health District $1974-8$. 
delivered in the same period, to determine differences between the two groups which may influence the outcome of pregnancy.

\section{Patients and methods}

Bradford Health District's Asian immigrant population comes principally from Pakistan, but also from India and Bangladesh. During the five years 1974-8, 6443 babies were born in Bradford to Asian mothers, and over the same period there were 18924 births to mothers who themselves had been born in Britain. The proportion of Asian births rose from $22 \%$ in 1974 to $28 \%$ in 1978 . Of the Asian babies born in 1978, 77\% were to Pakistani parents.

The district has smaller groups of immigrants from many parts of the world, including Europe, the West Indies, Africa, and the Middle East, but the number of babies born in Bradford to women of these and other ethnic groups and nationalities accounted for only 917 (35\%) of the five years' total births and these patients have been excluded from the present review.

Despite their dissimilar origins, at the time of the survey both the Asian immigrant and the British-born women lived in the same geographical area and shared the same maternity services. Over 98\% of the confinements under review took place in the district's two maternity hospitals, but the domiciliary confinements within the Bradford Health District have also been included.

Our data have been collected from the individual maternity records which are compiled for every patient delivered in Bradford. Information is routinely extracted and coded in the hospital records department and the basic computing is undertaken by the Yorkshire Regional Health Authority. The data include approximately 300 deliveries a year to mothers normally resident outside the district. These deliveries are, however, not included in the perinatal mortality figures, which relate only to births to mothers resident in Bradford.

Unless otherwise stated, the results quoted are based upon the total numbers of births in the five years surveyed, which were 6443 to Asian and 18924 to British-born mothers.

\section{Results}

THE MOTHERS

Asian mothers were older at confinement than British mothers. The proportion of births at the age of 35 and over was 3.6 times greater, and at age 40 and over seven times greater, for Asian women. In contrast, the proportion of teenage confinements of British mothers was almost twice that of Asians (Table 1).
The proportion of Asian mothers in Social Class V was more than six times that of British-born mothers (Asian 47\%, British 7\%).

The Asian mothers were shorter: $13 \%$ were less than $147 \mathrm{~cm}$ ( 58 inches) whereas only $3 \%$ of United Kingdom mothers were below that height.

Illegitimate births rarely occur in the Asian community and from $1974-8$ only $0.5 \%$ of Asian women were not married at the time of delivery. In contrast, illegitimate births to British-born mothers increased from 14\% in 1974 to $16 \%$ in 1978.

There were virtually no smokers among the Asian women (21 patients out of a total of 6443). Thirty-one per cent of the expectant mothers born in Britain admitted to smoking more than 10 cigarettes a day, and $10 \%$ admitted to smoking more than 20 cigarettes a day, at the time of their first visit to the antenatal clinic.

\section{PREVIOUS OBSTETRIC HISTORY}

The previous obstetric history is given in Table 2 . Only $24 \%$ of the Asian maternity patients were primiparous compared with $42 \%$ of indigenous mothers. The proportion of Asian women who had had four or more previous labours was sevenfold greater and the proportion with six or more previous labours 15 times greater. There has been a decline from 1974-8 in the proportion of high-parity women in both ethnic groups, but in 1978 Asian women were still 11 times more likely to have had five or more previous labours.

The proportion (37\%) of Asian maternity patients who had pregnancy intervals of less than one year was more than double that of British patients $(17 \%)$. This proportion did not change over the five years for the British mothers but for Asians it fell from $42 \%$ in 1974 to $36 \%$ in 1978. The proportion of Asian women who gave a history of one or more previous perinatal deaths was doubled (Asian 8\%, British 3\%), and four times as many Asian women reported two or more previous perinatal deaths (Asian 0.8\%, British $0.2 \%)$.

\section{PRESENT OBSTETRIC HISTORY}

Asian mothers tended to book late for their antenatal care (Table 3). Proportionately three times as many

Table 1 Age at confinement by maternal source, 1974-8

\begin{tabular}{llc}
\hline Age (years) & $\begin{array}{l}\text { United Kingdom } \\
\%\end{array}$ & $\begin{array}{c}\text { Asia } \\
\%\end{array}$ \\
\hline Under 20 & 15.3 & 8.2 \\
35 or over & 4.1 & 14.9 \\
40 or over & 0.9 & 6.3 \\
45 or over & 0.05 & 1.1 \\
Total patients (100\%) & 18924 & 6443 \\
\hline
\end{tabular}


Asian mothers had less than four months' antenatal supervision, whereas the proportion of Asian women who had six months or more of antenatal care was almost one-fifth that of the British patients. These figures showed no improvement from 1974-8.

As one index of maternal health during pregnancy, a comparison was made of the lowest recorded haemoglobin level. Six times as many Asian women had a level below 9g/dl (Asian 5\%, British 0.8\%), and three times as many Asian women had a level below $10 \mathrm{~g} / \mathrm{dl}$ (Asian 14\%, British 5\%).

\section{BIRTHS}

Twice as many of the Asian mothers and their babies experienced the hazard of delivery unattended by a midwife or doctor (Asian 1.8\%, British $\mathbf{0 . 7 \%}$ ). These figures showed no improvement over the five-year period.

In $2 \%$ of both Asian and British women the duration of pregnancy was recorded as uncertain. In those patients for whom an apparently reliable estimate of gestation was possible, nearly twice as many Asian women delivered before 38 weeks (Asian 17\%, British 9\%).

Thirteen per cent of the Asian babies born in the five-year period had a birth weight of $2500 \mathrm{~g}$ or below (British $8 \%$ ), and $4 \%$ of Asian babies weighed $2000 \mathrm{~g}$ or less at birth (British 3\%). (Table 4). The trend in both ethnic groups was to a reduction in low birth weight. The Asian babies, $2500 \mathrm{~g}$ or less, declined from $15 \%$ in 1974 to $12 \%$ in 1978 , during which time the proportion of low birth weights for babies born to British mothers fell from $9 \%$ to $8 \%$.

Table 2 Previous labours (live births and stillbirths) by maternal source, 1974-8

\begin{tabular}{lll}
\hline No. of labours & $\begin{array}{l}\text { United Kingdom } \\
\%\end{array}$ & $\begin{array}{l}\text { Asia } \\
\%\end{array}$ \\
\hline None & 42.2 & 24.3 \\
3 or more & 8.5 & 36.6 \\
4 or more & 3.4 & 24.4 \\
5 or more & 1.4 & 15.8 \\
6 or more & 0.6 & 9.4 \\
7 or more & 0.3 & 5.5 \\
Total patients (100\%) & 18924 & 6443 \\
\hline
\end{tabular}

Table 3 Duration of antenatal care by maternal source, 1974-8

\begin{tabular}{lll}
\hline & $\begin{array}{l}\text { United Kingdom } \\
\%\end{array}$ & $\begin{array}{l}\text { Asia } \\
\%\end{array}$ \\
\hline Less than 4 months & 20.2 & 60.7 \\
4 to 6 months & 47.8 & 32.0 \\
6 months or more & 31.2 & 6.8 \\
Not known & 0.9 & 0.5 \\
Total patients (100\%) & 18924 & 6443 \\
\hline
\end{tabular}

Table 4 Birth weight by maternal source, 1974-8

\begin{tabular}{lll}
\hline Weight $(g)$ & $\begin{array}{l}\text { Unired Kingdom } \\
\%\end{array}$ & $\begin{array}{c}\text { Asia } \\
\%\end{array}$ \\
\hline 1500 or under & 1.0 & 1.4 \\
$1501-2000$ & 1.6 & 2.4 \\
$2001-2500$ & 5.3 & 9.3 \\
2500 or under & 7.9 & 13.1 \\
2501 or over & 91.8 & 86.5 \\
Not known & 0.4 & 0.3 \\
Total births (100\%) & 18924 & 6443 \\
\hline
\end{tabular}

Whereas almost all the Asian mothers would have breast-fed their babies in their country of origin, in Bradford in 1974, 60\% did not even begin to breast-feed (British 63\%). In both ethnic groups the proportion who never breast-fed fell by approximately one-fifth during the five-year period, but still in 1978, 42\% of Asian mothers and 43\% of British mothers never breast-fed.

\section{Discussion}

Our survey indicates that different factors which could have an adverse effect on the outcome of pregnancy can be identified for Asian and British-born mothers. Although we are not attempting to quantify the effect of these different factors on perinatal mortality, some indication of their importance can be obtained by comparison with national perinatal data.

In England in 1977, the PNMR for infants born to women aged between 20 and 35 was 16 per 1000 . For women aged 16 to 19 , the rate was 22 per 1000 and for those aged 35 and over it increased to 24 per $1000 .^{\circ}$ In Bradford in 1977, 14\% of Asian mothers were aged 35 and over (British 3.5\%), and 6\% were 40 and over (British $0.7 \%$ ). Greater maternal age is therefore likely to contribute to the higher PNMR for Asian babies.

It is difficult to separate all the factors operating within the social class structure which affect perinatal mortality but the PNMR in England in 1977 for Social Class I was 11 per 1000 and for Social Class V it was 22 per $1000 .^{\circ}$ In Bradford in 1977, 46\% of Asian women were from Social Class V compared with $6 \%$ of British women, presumably placing the Asian mothers at a disadvantage. Many Asian men in Bradford are unskilled workers in the local textile industries and an increasing number are unemployed.

It is known for British births that there is a close correlation between maternal height and perinatal mortality-the shorter the mother the higher the PNMR. ' Asian women tended to be shorter than the British-born women and $2 \%$ were less than $142 \mathrm{~cm}$ (56 inches), small even by Asian standards.

The lowest PNMR occurs with the second child and is half that of the fifth child. In England in 1977 
the PNMR for babies whose mothers were gravida 2 was 13 per 1000; for those whose mothers were gravida 5 or above the rate was 28 per $1000 . .^{8}$ In Bradford in 1977, despite a downward trend over the five-year period, Asian women were 11 times more likely to have had five or more previous labours. In a separate review carried out by one of the authors into family planning clinic patients in Bradford, it was found that Asian women were older than the British-born at their first attendance and half were gravida 4 or above when first attending. ${ }^{8}$

The risks to the health of both mother and child are increased with short intervals beween successive pregnancies. Both prematurity and infant death rates rise as pregnancy intervals shorten. ${ }^{2}$ Proportionately twice as many Asian patients had pregnancy intervals of less than one year and therefore more were potentially at increased risk of a perinatal death.

Reproductive patterns tend to recur. The 1958 perinatal mortality survey found that the PNMR increased by between two and three times when there had been a previous stillbirth or neonatal death.' More than twice as many Asian as non-Asian mothers reported at least one previous perinatal death, but some of the earlier pregnancies of the immigrant women occurred in their country of origin.

Because of the high-risk factors already defined, Asian mothers should make full use of the comprehensive obstetric services from an early stage of pregnancy. It is therefore regrettable that $61 \%$ of the Asian patients had had less than four months' antenatal supervision and only $7 \%$ had received more than six months' antenatal care. There was no improvement in these figures over the period under review and indeed there has been little change since 1969.5 The reluctance of the Asian community to accept early antenatal care is probably due to many causes, but it is clear that the importance of attending antenatal clinics early in pregnancy has not been sufficiently appreciated by them. An attempt has been made to overcome language difficulties by employing interpreters in the antenatal clinics. Many patients who are booked for hospital confinement receive some of their antenatal care at local health centres, thus avoiding the need to travel greater distances to the maternity hospitals. Recent local health education programmes have been directed to both expectant mothers and their general practitioners. The dual approach has been made because in some cases women have had their pregnancies confirmed by the general practitioner at an early stage, but have not subsequently been referred to the antenatal clinics until several months have elapsed.

Apart from a few exceptional cases, mothers are encouraged to breast-feed their babies. Although the number of women attempting to breast-feed increased in both ethnic groups throughout the period under review, over $40 \%$ of Asian mothers in 1978 still fed their babies with artificial milks from birth. Bamford ${ }^{3}$ found by retrospective inquiry that a group of children born in Asia but now living in Bradford had all been breast-fed for a minimum of three months. A return to this normal cultural pattern would be desirable. Among other advantages, lactation helps towards spacing of pregnancies, and in Bangladesh, where almost all children are breast-fed for many months, the average birth interval is about two years. ${ }^{10}$

One of the purposes of this retrospective comparative study was to identify specific problems and risk factors for Asian maternity patients. Cultural, religious, and social differences, as well as physical and medical ones, play an important part in the successful outcome of pregnancy, and the former are not necessarily influenced by the provision of medical services and health education programmes. It would, however, appear to be worthwhile to direct health care resources towards known adverse factors. Encouraging expectant mothers to book early and attend regularly for antenatal care, to breast-feed their babies and space their pregnancies by at least one year, and to complete their families before the age of 40 should, if effective, help to diminish the PNMR for Asian patients in particular.

Reprints from Dr. K. M. Lumb, Joseph Brennan House, Sunbridge Road, Bradford BD1 2SY.

\section{References}

'Anonymous. Population Trends 18. London: Office of Population Censuses and Surveys, 1979: 1-7.

${ }^{2}$ Chamberlain G, Philipp E, Howlett B, Masters K. British Births 1970, vol. II: Obstetric Care. London: Heinemann Medical, 1978: 8-53.

3 Stanley F, Alberman ED. Infants of very low birth weight I: perinatal factors affecting survival. Dev Med Child Neurol 1978; 20: 300-12.

Anonymous. Caring for babies of very low birth weight. $B r$ Med J 1978; ii: $1105-6$.

'Bamford FN. Immigrant mother and her child. Br Med J 1971; i: $276-80$.

- OPCS Monitor. Infant and Perinatal Mortality. London: Office of Population Censuses and Surveys, 1979: 1-12.

${ }^{2}$ Chamberlain $\mathbf{R}$. The week. In: Chamberlain $\mathbf{R}$, Chamberlain G, Howlett B, Claireaux A. British Births 1970, vol I: The First Week of Life. London: Heinemann Medical, 1975: 9-42.

- Lumb KM, Pettinger CM. Family planning in an Asian immigrant population. Novum 1979; 4: 8-9.

'Butler RN, Bonham DG. Perinatal Mortality. First Report of 1958 British Perinatal Mortality Survey. London: Livingstone, 1963: 32-9.

${ }^{10}$ Anonymous. Interval between pregnancies. Lancet 1978; ii: $\mathbf{8 7 9 - 8 0}$. 